\title{
The patients' perspective: Results of a survey assessing knowledge about and attitudes toward depression in PD
}

\author{
Irene Hegeman Richard' \\ Kori A LaDonna' \\ Rosanne Hartman ${ }^{2}$ \\ Carol Podgorski' \\ Roger Kurlan' \\ SAD-PD Study Group ${ }^{3}$
}

'University of Rochester School of Medicine and Dentistry, Rochester, NY, USA; ${ }^{2}$ Canisius College, Buffalo, NY, USA; ${ }^{3}$ Please see Appendix for members of the SAD-PD Study Group

Correspondence: Irene Hegeman Richard University of Rochester School

of Medicine and Dentistry, I35 I Mt. Hope Avenue, Suite 100, Rochester, NY I4620,

USA

Tel + I 5852757937

Fax +I 5854734678

Email irene_richard@urmc.rochester.edu

\begin{abstract}
We report results of a survey assessing patients' knowledge about and attitudes towards depression in Parkinson's disease (PD). 345 patients from 8 tertiary care centers responded (43\% response rate). Overall, patients were relatively knowledgeable about depression and its occurrence in PD. However, many patients believed that depression is a normal reaction to the illness. While many respondents would be reluctant to initiate a discussion of depression during a clinical evaluation, most would feel comfortable talking about depression with their physician if he or she asked them questions about their mood. Based on the results of this survey, we recommend the following approach for physicians: (1) inform PD patients that, although a frequent occurrence, depression need not be accepted as a "normal reaction" to $\mathrm{PD}$; and (2) routinely inquire about depressive symptoms rather than waiting for the patient to spontaneously report them.
\end{abstract}

Keywords: depression, Parkinson's disease, survey

\section{Introduction}

Depression is common in PD with an estimated prevalence of $40 \%-50 \%$ (Mayeux et al 1986; Dooneif et al 1992; Tandberg et al 1996). Depression in PD has a negative impact on quality of life (Phillips 1999; Kuopio et al 2000; GPDS Steering Committee 2001). There is a range of severity in depression associated with PD (Liu et al 1997) and evidence that even the minor forms of depression significantly impair functional abilities (Liu et al 1997).

Evidence suggesting that depression in PD is probably a manifestation of underlying neurochemical and neuroanatomical alterations, rather than solely a reaction to disability, includes the following: (1) most studies have found patients with PD to be more depressed than other disabled patients matched for functional impairment (Wharburton 1967; Singer et al 1973; Ehmann et al 1990; Starkstein et al 1990; Menza et al 1994), (2) depression often antedates the parkinsonian motor symptoms (Horn 1974; Santamaria et al 1986; Ishihara 2006), and (3) there appears to be no clear-cut association between depression and stage of neurological illness (Cummings 1992). The precise relationship of depression to the underlying brain disease remains to be clarified.

There is evidence that depression in PD is under-diagnosed (GPDS Steering Committee 2001; Shulman et al 2002; Richard et al 2006) and under-treated (Weintraub et al 2003; Ravina et al 2007). Both patients and physicians may have difficulty recognizing depression in PD due to potential overlap between signs and symptoms of depression and those of PD itself(Marsh et al 2006). In addition, there is some evidence to suggest that the frequency with which particular depressive symptoms manifest may be different in patients with PD than in those without PD. For example, patients with PD tend to report fewer feelings of guilt or failure than patients without PD (Cummings 1992; 
Burn 2002). Also, the social stigma associated with depression may contribute to patients' reluctance to seek help (Hirschfeld et al 1997; Sirey et al 2001; Roeloffs 2003).

PD patients must not only be knowledgeable of the symptoms of depression, they must be willing to discuss any signs of the symptoms with their physician. We conducted the following study to assess knowledge of and attitudes towards depression in a sample of patients with PD.

\section{Methods}

Eight US academic neurology/psychiatry clinics specializing in the treatment of PD were included in this survey study. Institutional Review Boards at each center approved the study. Each of the eight sites used a computer-generated list of 100 patients randomly selected from a larger list of PD patients attending their clinic for a total of 800 mailings. A letter from each site's neurologist or psychiatrist describing the study was included. A cover letter provided instructions for completing the survey, an explanation of how others might help completing the survey if needed, and an emphasis on how the answers should reflect the experiences and opinions of the PD patient.

We created the survey specifically for this study based on the current body of knowledge about depression in the setting of PD (Richard 2006, 2007; McDonald et al 2003). Our aim was to understand knowledge base and attitude of PD patients and not in the construction of a measurement scale per se. The survey contained 19 statements about depression (including those intended to assess knowledge about depression, the relationship between depression and PD and attitudes about discussing depression with others).

Subjects were instructed to respond to questions using a 5-point Likert scale, a widely used psychometric response scale that measures attitude, providing a range of responses to a given question or statement (Likert 1932). Subjects could choose from one of the following responses for each item: strongly agree, agree, neither agree or disagree, disagree and strongly disagree.

The questionnaire requested that patients record their age, gender and duration of PD and answer yes or no to five questions about their personal psychiatric history. Simple frequencies were tallied to represent how often respondents agree and disagree with the statements.

\section{Results}

\section{Study respondent characteristics}

Out of 800 surveys mailed, 49 were returned because the address was incorrect or the patient was deceased. A total of 345 surveys were completed and returned, for a response rate of $43 \%$. The respondents ranged in age from 34-95 years (mean age $=67.1$ years) and $36 \%$ were female. $3.5 \%$ of the patients had been diagnosed with PD for less than one year, 38\% for $1-5$ years, $25.4 \%$ for $6-10$ years and $32.4 \%$ for over 10 years. Thirty-two percent reported having been diagnosed with depression; 37.5\% had been evaluated by a mental health professional, $45.6 \%$ had taken medication to help with their mood and $33.7 \%$ had a family member diagnosed with depression.

\section{Survey responses}

Responses to individual items are summarized in Table 1. In general, this group of respondents demonstrated that they were knowledgeable about many aspects of depression. Ideational symptoms and, to a slightly lesser extent, somatic symptoms of depression were recognized by the majority of respondents. The vast majority of patients knew that depression can be associated with reduced quality of life. The majority of patients realized that depression was common in PD but more than half considered it to be a normal reaction to the illness. While the majority of subjects were open to the idea of treatment, many responses indicated that a substantial minority perceived stigma surrounding depression. Many patients would be more comfortable to talk to their doctor than their family about depressive symptoms and would be more apt to discuss the issue if their physician initiated the conversation.

\section{Conclusion}

In general, our sample of PD patients was knowledgeable about depression but the majority of respondents believe that it is a normal reaction to the illness. There continues to be a stigma surrounding depression, even among this relatively knowledgeable group of patients. Many patients would be reluctant to talk about depression with their family or friends. PD patients may be hesitant to bring up depression with their physicians but would be willing to talk about symptoms of depression when the discussion is physician initiated.

There are several methodological limitations to our study that should be considered when interpreting the results. First, our group of respondents is likely to represent a highly selective sample of PD patients. Questionnaires were mailed only to patients at tertiary care academic and research-focused centers and slightly less than half returned completed surveys. Approximately one-third of responders reported having been diagnosed with depression. Thus, our 


\begin{tabular}{|c|c|c|c|}
\hline Survey items & Agree (\%) & Neutral (\%) & Disagree (\%) \\
\hline Symptoms of depression are rarely seen in people with PD & 12 & 20 & 68 \\
\hline Depression is a normal reaction to having PD & 58 & 24 & 18 \\
\hline There are medications that can treat depression & 88 & 8 & 4 \\
\hline Taking medications for depression is seldom necessary & 8 & 24 & 68 \\
\hline Sleep patterns are not affected by depression & 14 & 10 & 76 \\
\hline People with depression may notice changes in their weight & 60 & 30 & 10 \\
\hline Decreased sexual desire is not a symptom of depression & 16 & 25 & 59 \\
\hline Depression can cause a decreased quality of life & 90 & 4 & 6 \\
\hline It is possible to become depressed even when things are going well & 82 & 11 & 7 \\
\hline There is no difference between depression and feeling "blue" & 13 & 20 & 67 \\
\hline Depression can make someone question if life is worth living & 84 & 8 & 8 \\
\hline $\begin{array}{l}\text { Depression is an illness, like heart disease or diabetes, that has to be } \\
\text { diagnosed and treated by health care professionals }\end{array}$ & 88 & 7 & 5 \\
\hline I would know if I had depression & 46 & 24 & 30 \\
\hline Most people can get over depression if they put their minds to it & 15 & 24 & 61 \\
\hline People would view me differently if they knew I had depression & 44 & 37 & 18 \\
\hline $\begin{array}{l}\text { If I were diagnosed with depression, I would be willing to see a mental } \\
\text { health professional to get counseling }\end{array}$ & 84 & 11 & 5 \\
\hline $\begin{array}{l}\text { If I felt depressed, I would be hesitant to talk to my family and friends } \\
\text { about it }\end{array}$ & 38 & 16 & 46 \\
\hline $\begin{array}{l}\text { I would feel comfortable talking about depression with my physician } \\
\text { if he or she asked me questions about my mood }\end{array}$ & 86 & 8 & 6 \\
\hline $\begin{array}{l}\text { I would be reluctant to bring up the issue of depression during } \\
\text { an evaluation with my physician }\end{array}$ & 17 & 16 & 67 \\
\hline
\end{tabular}

Agree = percentage of subjects responding either "Strongly Agree" or "Agree". Neutral = percentage of subjects responding "Neither Agree nor Disagree".

Disagree $=$ percentage of subjects responding "Disagree" or "Strongly Disagree".

sample may be better informed about PD and depression than the typical PD patient. Second, our survey was created specifically for this study and has not undergone validity and reliability testing. Third, this was an anonymous self-report survey and objective evaluations were not conducted. We know that the average age and gender distribution was typical of PD and that there was a fairly evenly distributed range of disease duration. However, we do not have detailed clinical information (eg, motor, cognitive or psychiatric status) to consider when interpreting our results.

Future research may provide data with which to draw more definitive conclusions regarding the knowledge and attitudes about depression in PD. Such studies might include administration of the questionnaire to other populations (eg, community sample of PD patients, healthy controls) and direct assessment of patients in order to correlate survey responses with clinical characteristics. However, the results of this study do provide data to support the following recommendations to physicians: (1) inform PD patients that depression, while common in $\mathrm{PD}$, is an abnormal emotional state that can be diagnosed and treated; and (2) remember to inquire about depressive symptoms when treating PD patients.

\section{Acknowledgment}

This study was supported by NIH/NINDS grants "Mood Fluctuations in Parkinson's Disease" (\#5 K23 NS02184) and "Serotonergic Antidepressant in Parkinson's Disease (SAD-PD) Planning Grant” (R21 \#NS43183).

\section{References}

Burn DJ. 2002. Beyond the iron mask: towards better recognition and treatment of depression associated with Parkinson's disease. Movement Disorders, 17:445-54.

Cummings J. 1992. Depression and Parkinson's disease. A review. Am J Psychiatry, 149:443-54

Dooneif G, Mirabello E, Bell K, et al. 1992. An estimate of the incidence of depression in idiopathic Parkinson's disease. Arch Neurol, 49:305-7.

Ehmann T, Beninger R, Gawel M. 1990. Depressive symptoms in Parkinson's disease: a comparison with control subjects. $J$ Geriatr Psychiatry Neurol, 2:3-9.

[GPDS Steering Committee] The Global Parkinson's Disease Survey (GPDS) Steering Committee. 2001. Factors impacting on quality of life in Parkinson's disease: Results from an international survey. Mov Disord, 17:60-7.

Hirschfeld RM, Keller MB, Panico S, et al. 1997. The National Depressive and Manic-Depressive Association consensus statement on the undertreatment of depression. JAMA, 277:333-40.

Horn S. 1974. Some psychological factors in parkinsonism. J Neurol Neurosurg Psychiatry, 37:27-31.

Ishihara L, Brayne C. 2006. A systematic review of depression and mental illness preceding Parkinson's disease. Acta Neurologica Scandinavica, 113:211-20. 
Kuopio A, Marttila R, Hellenius H, et al. 2000. The quality of life in Parkinson's disease. Mov Disord, 15:216-23.

Likert RA, 1932. A technique for the measurement of attitudes. Arch Psychol, 140:5-55.

Liu C-Y, Want S-J, Fuh J-L, et al. 1997. The correlation of depression with functional activity in Parkinson's disease. J Neurol, 244:493-8.

Marsh L, McDonald WM, Cummings J, et al. 2006. Provisional diagnostic criteria for depression in Parkinson's disease: Report of a NINDS/NIMH Work Group. Movement Disorders, 21:148-58.

McDonald WM, Richard IH, DeLong MR. 2003. Prevalence, etiology, and treatment of depression in Parkinson's disease. Biological Psychiatry, 54:363-75.

Menza MA, Mark MH. 1994. Parkinson's disease and depression: the relationship to disability and personality. J Neuropsychiatry Clin Neurosci, 6:165-9.

Phillips P. 1999. Keeping depression at bay helps patients with Parkinson's disease. JAMA, 282:1118-19.

Ravina B, Camicioli R, Como PG, et al. 2007. The impact of depressive symptoms in early Parkinson disease. Neurology, 69:342-7.

Richard IH. 2006. Apathy does not equal depression in Parkinson disease: Why we should care. [editorial] Neurology, 67:10-11.

Richard IH. 2007. Depression and apathy in Parkinson's disease. Curr Neurol Neurosci Rep, 7:295-301.

Richard IH, Kurlan R. 2006. The under-recognition of depression in Parkinson's disease. Neuropsychiatric Disease and Treatment, 2:349-53.

Roeloffs C, Sherbourne C, Unutzer J, et al. 2003. Stigma and depression among primary care patients. General Hospital Psychiatry, 25:311-15.

Santamaria J, Tolosa E, Valles A. 1986. Parkinson's disease with depression: a possible subgroup of idiopathic parkinsonism. Neurology, 36:1130-3.

Shulman LM, Taback RL, Rabinstein AA, et al. 2002. Non-recognition of depression and other non-motor symptoms in Parkinson's disease. Parkinsonism and Related Disorders, 8:193-7.

Singer E. 1973. The effect of treatment with levodopa on Parkinson patients social functioning and outlook on life. J Chronic Dis, 27:581-94.

Sirey JA, Bruce ML, Alexopoulos GS, et al. 2001. Perceived stigma and patient-rated severity of illness as predictors of antidepressant drug adherence. Psychiatric Services, 52:1615-20.

Starkstein S, Prezios T, Bolduc P, et al. 1990. Depression in Parkinson's disease. J Nerv Ment Dis, 178:27-31.

Tandberg E, Larsen J, Aarsland D, et al. 1996. The occurrence of depression in Parkinson's disease: a community-based study. Arch Neurol, 53:175-9.

Weintraub D, Mobertg PJ, Duda JE, et al. 2003. Recognition and treatment of depression in Parkinson's disease. J Geriatr Psychiatry Neurol, $16: 178-83$.

Wharbuton J. 1967. Depressive symptoms in Parkinson's patients referred for thalamotomy. J Neurol Neurosurg Psychiatry, 30:368-70.

\section{Appendix}

The following members of the SAD-PD Study Group participated in the "Serotonergic Antidepressant in Parkinson's Disease (SAD-PD) Planning Grant" study and contributed to this report: I. Richard, principal investigator, University of Rochester, Rochester, William McDonald, co-principal investigator, Emory University, Atlanta, N. Pearson, project manager, University of Rochester, Rochester; Participating treating investigators and coordinators: Oregon Health and Science University, Seattle: M. Brodsky, Michele Barnard, Albany Medical College, Albany: S. Factor, J. Nash, Memorial Hospital of Rhode Island/Brown University, Pawtucket: J. Friedman, L. Tobia, University of Rochester, Rochester: R. Kurlan, C. Deeley, Johns Hopkins University, Baltimore: L. Marsh, M. Gerstenhaber, Emory University, Atlanta: J. Juncos, B. Sommerfeld, University of Maryland, Baltimore: L. Shulman, K. Dustin, Columbia University, New York: C. Waters, R. Benabou. 